\title{
The Incorporation of a Materials Selection Program in a Junior-Level Me- chanical Engineering Design Course
}

\section{Mr. Elliott Vega, University of Washington, Bothell}

Elliott Vega is an senior undergraduate mechanical engineer enrolled at the University of Washington Bothell. He received his Associate in Science degree from Shoreline Community College in 2014 in preengineering and was accepted as part of the first cohort to enroll as a mechanical engineer at the Bothell campus. His current interest and focus is to apply the knowledge gained in the classroom to advanced vehicle modifications. Upon graduating, he plans on pursuing a career in the automotive industry or manufacturing industry.

\section{Dr. John William Bridge, University of Washington, Bothell}

Dr. John Bridge, P.E. Dr. Bridge is a former Lt. Colonel and mechanical engineer in the U.S. Air Force with over twenty years of $R \& D$ experience with numerous aerospace vehicles to include aircraft and rocket systems. In addition, he has performed advanced materials characterization while in the military and at Lawrence Livermore National Laboratory. He has previous teaching experience at several institutions to include Bowdoin College, the U.S. Air Force Academy, and the U.S. Military Academy at West Point. Dr. Bridge is currently working with composite materials used in synthetic sports surfaces to include Thoroughbred horse racetracks. His focus is on the thermal and mechanical characterization of wax/polymer binders, and on the mechanisms of polymer adhesion and environmental degradation. Dr. Bridge also collaborates with the Racetrack Surfaces Testing Laboratory in Orono, Maine and with Lab/Cor Materials laboratory in Seattle. 


\title{
The Incorporation of a Materials Selection Program in a Junior-Level Mechanical Engineering Design Course
}

\begin{abstract}
An undergraduate, junior-level machine design class at the University of Washington, Bothell was modified to incorporate a material selection design textbook with an associated professionallevel software program. Materials selection concepts and methods were interspersed throughout the course and integrated into three student-group design projects involving springs, bearings, rotating shafts, and gear elements. This approach resulted in a practical and effective method of introducing materials selection into the design process and provided needed skills for the followon, senior-level capstone design course. At the end of the class, an easy-to-follow, studentwritten material selection reference guide (with examples) was produced to provide guidance for future classes and students needing a quick overview of the materials selection process and use of the materials selection software.
\end{abstract}

